\title{
The Need for Measuring Transformative Experiences in Engineering Educa- tion
}

\section{Dr. Katherine Goodman, University of Colorado, Denver}

Katherine Goodman is assistant professor at the University of Colorado Denver, in Inworks, an interdisciplinary innovation lab. She completed her PhD at the ATLAS Institute in Technology, Media, and Society at the University of Colorado Boulder. Her research focuses on experiential learning in engineering education. She also holds a B.S. in mathematics and a masters of professional writing.

\section{Dr. Jean Hertzberg, University of Colorado, Boulder}

Dr. Hertzberg is currently Associate Professor of Mechanical Engineering at CU-Boulder. She teaches graduate and undergraduate courses in measurement techniques, thermodynamics, fluid mechanics, heat transfer, design and computer tools. She has pioneered a spectacular course on the art and physics of flow visualization, and is conducting research on the impact of the course with respect to visual perception and educational outcomes. Her disciplinary research centers around pulsatile, vortex dominated flows with applications in both combustion and bio-fluid dynamics. She is also interested in a variety of flow field measurement techniques. Current projects include electrospray atomization of jet fuel and velocity and vorticity in human cardiac ventricles and large vessels. 


\section{The Need for Measuring Transformative Experiences in Engineering Education}

\section{Abstract}

Transformative experiences (TE) are specific moments when students 1) apply practices and/or knowledge from their coursework to everyday experiences without prompting (also called motivated use); 2) view everyday objects or situations through the lens of course content (expanded perception); and 3) express value course content in new ways because it enriches everyday experience (experiential value, which we also term affective value). This construct draws heavily on John Dewey's seminal work in education and experiential learning. Transformative experience has been measured in science courses at both the K-12 and undergraduate levels; work is very preliminary in engineering. Here, we explain the import of fostering transformative experiences, particularly in the context of engineering design. We describe differences between transformative experiences of scientific topics and those of engineering principles. We also draw connections between transformative experience and belonging and engineering identity, which are being measured more frequently in the process of recruitment and retention of students.

\section{Challenges in Growing the Number of Engineers}

Engineering students often cannot or do not apply what they learned while earning engineering degrees in engineering workplaces ${ }^{1}$. Perhaps graduates do not see how their courses connect with real situations they encounter on the job. Perhaps they do see the connections, but they do not want to use what they learned, professionally. Which part of this is the true problem? Or is it a messy combination of both?

Beyond school, students quickly discover their theoretical knowledge, or even their ability to apply that knowledge, is less important than what they are willing to do with that knowledge. Even when students can make the necessary connections, some find they are uninterested in doing so ${ }^{1-3}$. It is difficult, at times, to tell the difference between the students who cannot use, in the real world, the skills they have gained in school and those who can, but choose not to.

This two-part problem is expressed in a number of interesting findings. For example, there has been a push for institutions of higher education to produce greater numbers of qualified engineers, and more broadly, qualified professionals in all of the STEM (science, technology, engineering, mathematics) disciplines ${ }^{4,5} \mathrm{~A}$. This effort is fueled by the industry view that engineers are innovators and therefore, their work fuels economic growth. In fact, one study called innovation the "integrative, meta-attribute" employers expect of all engineering graduates ${ }^{6}$. In addition, there are calls to create "an increasingly diverse talent pool"7, and evidence that more diverse groups of employees are, in fact, more innovative ${ }^{8}$.

\footnotetext{
A There are dissenters to this argument, such as Teitelbaum, who claim we are creating a boomand-bust cycle of STEM professionals, and there is no pointed need to significantly increase the number of engineering graduates at the current time ${ }^{49}$. Even if this argument proves to be true, improving the efficacy of engineering education will create a steady supply of motivated and welltrained engineers, a goal Teitelbaum supports.
} 
One challenge universities face in meeting that demand is high rates of attrition among engineering majors. Many studies document the "leaky pipeline," and strive to understand the reasons students leave STEM programs during their undergraduate years ${ }^{3,9-12}$. These attrition studies frequently reveal that women and under-represented minorities leave in numbers disproportionate to their presence in the programs ${ }^{9,13}$. One answer might be that those who leave STEM degree programs are incapable or unprepared ${ }^{\mathrm{B}}$, but the data do not support this as the sole cause. While many students do leave because of lower academic performance, many do not ${ }^{3}$. One study discovered that women who leave STEM programs have the same GPAs as women who stay ${ }^{13}$, and another found that women who leave have higher GPAs than the men who remain ${ }^{9}$. These findings suggest that more is going on than simply "weeding out" the students who "don't have what it takes" to learn engineering.

We should also acknowledge that education is a formative process during which we make discoveries about what we can do and what we want to do. Of course, some students will leave their STEM majors. When students leave, we want it to be because they have located a more authentic passion, not because they are fleeing poor teaching and a combative environment.

Unfortunately, students are leaving for those reasons. We know this through studies such as the seminal "Talking about Leaving" 9 , which documented attrition rates for science, math, and engineering majors across seven four-year institutions of higher education and reported its findings in chapters with names including "The Weed-Out Process" and "The Unsupportive Culture." Since that time, various other studies have documented similar struggles of students who choose to leave STEM majors ${ }^{3,14,15}$. Whether we work to correct this through improved pedagogy or shifts in cultural climate, or both, raising retention rates within our programs would obviously create more engineering graduates.

Yet, is degree completion our only concern? The majority of STEM-degree holders do not work in a STEM field, according the US Census Bureau ${ }^{2}$. Many students leave engineering and other STEM disciplines as they enter the workforce ${ }^{5,16}$. In addition, there is evidence that the highestachieving students in U.S. engineering programs do not go on to work in engineering ${ }^{16}$. While poor economic circumstances may have made finding a job a challenge for many recent graduates, surely top students had a choice in their professions. If we are asking "why don't more students complete engineering degrees?" we only address part of the problem. Perhaps the question should be "why don't more engineers enter the workforce?"

So, it is not enough to track student progress within a degree program or to target higher rates of degree completion. We need to understand more about why some students persist in using the skills and knowledge they develop while earning their degrees and others do not. We need to understand what motivates (or demotivates) them to use their engineering skills beyond the classroom.

в There is a distinct difference between incapable and unprepared, as the GoldShirt program as University of Colorado Boulder has demonstrated, where students from underrepresented groups are often successful after a "performance-enhancing" year ${ }^{50}$. 
Approaches to Answer the "Can they?" Question

Much of engineering education research targets individual engineering courses, and is focused on refining content, developing assessment tools, or creating more interactive classrooms ${ }^{17-19}$. These types of studies ask questions such as "are we teaching the right content?", "do our assessments actually measure whether students learn it?", and "does a particular change improve student outcomes on the assessments we developed?" These are important questions, worth answering.

Once we address whether students are learning what we want them to learn, the next question becomes, can they transfer that knowledge and skill from the classroom to the workplace? This question is sometimes called the "transfer problem" ${ }^{20}$, but it also appears under other names including "awareness" 21 , or the "need to activate resources" 22 . Educators who are aware of the situated nature of learning can intentionally develop learning environments that provide appropriate scaffolding for students ${ }^{23}$. However, without this awareness, the contextual backdrop can become a veneer, inhibiting students from seeing how their new knowledge or skills can be applied in other contexts, what Engeström calls encapsulation ${ }^{24}$. As a result, engineering students who learn only through structured problem sets may not know how to apply that knowledge once in the workplace ${ }^{25}$.

In response to these findings, there has been an increasing emphasis on design courses and capstone projects, which aim to have students integrate their skills in a single long term project. Such courses provide the opportunity to develop and measure a number of professional skills, including communication and teamwork ${ }^{25,26}$. These abilities are often called "soft skills" although some engineering educators would rather they be called "the missing basics", because they are essential for students to become successful engineers ${ }^{27}$.

One team has developed measures for how well students can demonstrate contextual competence $^{28}$, defined as “an engineer's ability to anticipate and understand the constraints and impacts of social, cultural, environmental, political, and other contexts on engineering solutions" 29 . This work goes beyond simple notions about transferring learning from one context to the next, and defines the broader arena in which engineers work. The focus on whether students have the ability to be successful in the engineering workplace represents only one half of the two-part problem. The unanswered question is whether they want to ${ }^{16}$.

Approaches to Answer the "Will they?" Question

It is only recently, and somewhat reluctantly, that engineering educators have openly addressed motivation and other emotionally-charged constructs as important components in what we do. In a 2015 editorial about efforts to improve engineering education through the creation of Olin College in Massachusetts and the iFoundry at the University of Illinois, Goldberg and Somerville noted that "all the relevant change variables are emotional." Perhaps more importantly, they confessed that "this was excruciatingly hard for a couple of engineers to understand and embrace, but once we did, we knew there was no going back" ${ }^{30}$. This acknowledgement of students' emotional experiences changes the direction for reform efforts from the narrow scope 
of pedagogy and curricular support to a broader conversation that includes student engagement and the development of a supportive community. Efforts to understand student self-efficacy have included studies of identity, or whether students think of themselves as engineers ${ }^{31,32}$, and defining what is meant by "continuing motivation," other than simply staying in a degree program $^{33}$.

Some efforts should concentrate, then, on creating supportive environments within engineering to help retain students, while others focus on developing courses and projects that provide a window into what working life as an engineer is like. These broader initiatives should work in tandem with efforts within our courses. Many of these initiatives must take place at the administrative level to be effective ${ }^{34,35}$. Without administrative support and relevant incentives for individual professors, reform efforts often fade, although a review of multiple studies also shows that change cannot be mandated in a top-down approach ${ }^{36}$. Individual professors should reshape their courses with these issues in mind. However, it can be difficult to bring these different facets of student experience into focus, and understand what is possible within a specific course. What guiding principles can we use in designing courses, if our goal as engineering educators is to address both the "can they?" and "will they?" questions?

Why the Transformative Experience

The transformative experience (TE) becomes a useful theoretical lens for engineering education because it helps bring into focus many of the challenges touched upon here. Science education researcher Kevin Pugh defined the transformative experience as one that changes the student, causes shifts of perception in a profound way, and is distinguished by three qualities:

1) The student applies ideas from coursework to everyday experiences without prompting (motivated use);

2) sees everyday objects or situations through the lens of course content (expanded perception); and

3) values course content in new ways because it enriches everyday affective experience (experiential or affective value $)^{37-39}$.

There is congruence between these three qualities and the two-part problem as outlined above. Motivated use is a sign that students are interesting in using their engineering talents beyond school, expanded perception is an indicator that students are successfully "transferring" the knowledge to new contexts, and affective value asks how students find personal significance what they are learning.

Pugh and Girod explored the origins of TE in John Dewey's work in a 2007 paper titled "Science, Art, and Experience: Constructing a Science Pedagogy from Dewey's Aesthetics." In that paper, they showed how the TE was developed from Dewey's educational philosophy of learning through experience ${ }^{40}$, combined with Dewey's observations on the power of our experiences with art ${ }^{41}$. Dewey describes art's power as much more than temporary delight or 
distraction. The power of art flows from its ability to change how we perceive the world, to show us new significance in our experiences.

This is an emotional experience, one that can occur, not only with art, Pugh and Girod contend, but also in the natural world, and more to our purposes, with scientific ideas. The transformative experience is not about noticing great scientific ideas in everyday life mechanistically or rationally. It means allowing ourselves, in big ways and small, to get swept away by those ideas, to really feel the impact those ideas can have on us and the world around us. It means allowing ourselves and our students to "geek out" about what they are learning, and more specifically for engineering, about what they can now do.

\section{From Science Education to Engineering Education}

The concept of the transformative experience has been converted into surveys and observational protocols to discover student engagement in the sciences among elementary school students 42,43 as well as high school and college students ${ }^{38,44}$. These studies have focused on geology and biology. Do they translate well from scientific learning to engineering learning? As Johri, Roth, and Olds ${ }^{45}$ point out, the directions of scientific inquiry and engineering design are often in opposite directions; that is, science is the process of collecting observations of the world, and abstracting them into representations of broadly-relevant knowledge. Engineering design is the practice of understanding that knowledge and creating a contextually-specific system in the world - a bridge, a spacecraft, a software package. These may seem diametrically opposed processes, and yet Johri et al. also point out the cyclical nature of how we reference and use knowledge between science and engineering, that engineers also create new scientific understanding, that can be abstracted and applied to other situations, and scientists test their ideas by designing experiments that by definition, have context-specific constraints. Although different, the two "ways of knowing" are not so opposed to prevent us from borrowing measures of the transformative experience. Surveys on TE, such as the one utilized by Heddy and Sinatra $^{44}$, could easily be converted to ask about engineering content rather than biology. These adapted surveys would require revised validation to verify that they measure the intended effect.

Already, there have been engineering education studies that suggest gauging TE would be beneficial. Several qualitative studies of engineering courses that investigated expansion of perception also found emergent patterns of students expressing affective value of topics such as fluid dynamics or engineering design ${ }^{46-48}$. These indicators arose in open-response survey questions and during interviews. Often the strongest expressions of affective value for specific engineering concepts came in response to questions about engineering identity, suggesting a new route for investigating the emergence of engineering identity.

As we continue to study the courses associated with these earlier studies and have adapted our survey questions to probe issues of motivated use, expansion of perception, and affective value, the most potent examples of TE continue to be the unsolicited reactions of students to a course, an instructor, or a particular facet of their newly developed skills or knowledge. Quantitative studies, utilizing closed-response survey questions that have been tested for reliability and validity, may always need to be augmented with qualitative inquiry - asking which parts of 
students' educational experiences have most contributed to their ability and willingness to work as engineers.

Conclusion

Institution-level metrics of engineering student persistence and graduation rates do not answer the ultimate question: have we added to the numbers of engineers in the workforce? Census data suggest a disconnect between graduation rates and numbers of those entering the workplace. The two issues embedded in that question are whether graduates of engineering programs have adequately learned the knowledge and skills needed for engineering careers, and whether our graduates want to use their newly gained knowledge and skills.

Issues of students' learning and motivation may best be detected at the course level, rather than at the institutional one. Asking questions that look into whether students have had transformative experiences with the course material allows us to find the moments that may have the most saliency for students. While not all students will experience an "a-ha" moment during the same activities, we can increase the likelihood by discovering what, if any, similarities exist among those moments. What prompts motivated use, or the expansion of perception that signals greater student engagement with a particular topic? When do students attach affective value to their work, and how does that develop into engineering identity? These are questions that can allow us, as engineering educators, to ultimately influence the growth of engineering students becoming engineers.

\section{Works Cited:}

1. Landivar, L. C. The Relationship Between Science and Engineering Education and Employment in STEM Occupations. Am. Community Surv. Reports 2-19 (2013).

2. US Census Bureau. Census Bureau Reports Majority of STEM College Graduates Do Not Work in STEM Occupations. (2014).

3. Chen, X. STEM Attrition: College Students' Paths Into and Out of STEM Fields: Statistical Analysis Report (NCES 2014-001). (2013).

4. My College Options \& STEMconnector. Where are the STEM Students? Where are the STEM Jobs ? 25 (2012).

5. National Science Board. Science and Engineering Labor Force. Science and Engineering Indicators 22 Suppl 1, (2010).

6. Radcliffe, D. F. Innovation as a Meta-Attribute for Graduate Engineers. Int. J. Eng. Educ. 21, 194-199 (2005).

7. National Academy of Engineering. The Engineer of 2020: Visions of Engineering in the New Century. (National Academies Press, 2004).

8. Page, S. E. The Difference: How the Power of Diversity Creates Better Groups, Firms, Schools, and Societies. (Princeton UP, 2007). 
9. Seymour, E. \& Hewitt, N. M. Talking about Leaving: Why Undergraduates Leave the Sciences. Contemporary Sociology 26, (Westview Press, 1997).

10. Moller-Wong, C. \& Eide, A. An engineering student retention study. J. Eng. Educ. 86, 715 (1997).

11. Imbrie, P. K., Lin, J. J.-J. \& Reid, K. Comparison of four methodologies for modeling student retention in engineering. in ASEE Annual Conference and Exposition, Conference Proceedings (2010).

12. Knight, D. W., Carlson, L. E. \& Sullivan, J. F. Improving Engineering Student Retention through Hands-On, Team Based,First-Year Design Projects. in 31st International Conference on Research in Engineering Education 1-13 (2007).

13. Blickenstaff, J. C. Women and science careers: leaky pipeline or gender filter? Gend. Educ. 17, 369-386 (2005).

14. Thompson, P. et al. Failing the Future: Problems of persistence and retention in science, technology, engineering, and mathematics (STEM) majors at Arizona State University. Tempe, AZ. Office of the ... (2007).

15. Chesler, N. C., Barabino, G., Bhatia, S. N. \& Richards-Kortum, R. The pipeline still leaks and more than you think: A status report on gender diversity in biomedical engineering. Ann. Biomed. Eng. 38, 1928-1935 (2010).

16. Lowell, B. L., Salzman, H., Bernstein, H. \& Henderson, E. Steady as She Goes? Three Generations of Students through the Science and Engineering Pipeline. Annu. Meet. Assoc. Public Policy Anal. Manag. 1-57 (2009).

17. Fraser, D. M., Pillay, R., Tjatindi, L. \& Case, J. M. Enhancing the Learning of Fluid Mechanics Using Computer Simulations. J. Eng. Educ. 381-388 (2007).

18. Prince, M., Vigeant, M. \& Nottis, K. Development of the heat and energy concept inventory: Preliminary results on the prevalence and persistence of engineering students' misconceptions. J. Eng. Educ. 101, 412-438 (2012).

19. Stern, F. et al. Hands-On CFD Educational Interface for. J. Eng. Educ. 63-83 (2006).

20. Pea, R. D. Socializing the knowledge transfer problem. Int. J. Educ. Res. 11, 639-663 (1987).

21. Rodd, M. Geometrical Visualisation--Epistemic and Emotional. Learn. Math. 30, (2010).

22. Hammer, D., Elby, A., Scherr, R. E. \& Redish, E. F. Resources, framing, and transfer. Transf. Learn. from a Mod. Multidiscip. Perspect. 89-120 (2005).

23. Brown, J. S., Collins, A. \& Duguid, P. Situated Cognition and the Culture of Learning. Educ. Res. 18, 32-42 (1989).

24. Engeström, Y. Non Scolae Sed Vitae Discimus: Toward Overcoming the Encapsulation of School Learning. Learn. Instr. 1, 243-259 (1991).

25. Lattuca, L. R., Terenzini, P. T., Volkwein, J. F. \& Peterson, George, D. The Changing 
Face of Engineering Education. Bridg. 36, 5-13 (2006).

26. Gilbuena, D. M., Sherrett, B. U., Gummer, E. S., Audrey, B. \& Koretsky, M. D. Feedback on Professional Skills as Enculturation into Communities of Practice. J. Eng. Educ. 104, 7-34 (2015).

27. Goldberg, D. E. \& Somerville, M. A Whole New Engineer. (threejoy, 2014).

28. Ro, H. K., Merson, D., Lattuca, L. R. \& Terenzini, P. T. Validity of the Contextual Competence Scale for Engineering Students. J. Eng. Educ. 104, 35-54 (2015).

29. Ro, H. K., Lattuca, L. R., Merson, D., State, P. \& Terenzini, P. T. Measuring Engineering Students' Contextual Competence. in American Society for Engineering Education (2012).

30. Goldberg, D. E. \& Somerville, M. Guest Editorial The Making of A Whole New Engineer : Four Unexpected Lessons for Engineering Educators and Education Researchers. J. Eng. Educ. 104, 2-6 (2015).

31. Knight, D. The Impact of Inclusive Excellence Programs on the Development of Engineering Identity among First-Year Underrepresented Students (\#7553). in ASEE Annual Conference and Exposition, Conference Proceedings (2013).

32. Johri, A. \& Olds, B. M. Situated Engineering Learning : Bridging Engineering Education Research and the Learning Sciences. J. Eng. Educ. 100, 151-185 (2011).

33. Fortus, D. \& Vedder-Weiss, D. Measuring students' continuing motivation for science learning. J. Res. Sci. Teach. 51, 497-522 (2014).

34. Muncey, D. E. ; \& McQuillan, P. J. Reform and Resistance in Schools and Classrooms: An Ethnographic View of the Coalition of Essential Schools. (Yale University Press, 1996).

35. Menand, L. The Marketplace of Ideas: Reform and Resistance in the American University (Issues of Our Time). (WW Norton and Company, 2010).

36. Henderson, C., Beach, A. \& Finkelstein, N. Facilitating change in undergraduate STEM instructional practices: An analytic review of the literature. J. Res. Sci. Teach. 48, 952984 (2011).

37. Pugh, K. J. Transformative Experience: An Integrative Construct in the Spirit of Deweyan Pragmatism. Educ. Psychol. 46, 107-121 (2011).

38. Pugh, K. J., Linnenbrink-Garcia, L., Koskey, K. L. K., Stewart, V. C. \& Manzey, C. Motivation, learning, and transformative experience: A study of deep engagement in science. Sci. Educ. 94, 1-28 (2010).

39. Pugh, K. J. \& Girod, M. Science, Art, and Experience: Constructing a Science Pedagogy From Dewey's Aesthetics. J. Sci. Teacher Educ. 18, 9-27 (2007).

40. Dewey, J. Experience and Education. (Touchstone by Simon \& Schuster, 1938).

41. Dewey, J. Art as Experience. (Perigee by Penguin Group, 1934). 
42. Pugh, K. J. Newton's laws beyond the classroom walls. Sci. Educ. 88, 182-196 (2004).

43. Fleer, M. \& March, S. Engagement in science, engineering and technology in the early years: A cultural-historical reading. Rev. Sci. Math. ICT ... 3, 23-47 (2009).

44. Heddy, B. C. \& Sinatra, G. M. Transforming Misconceptions: Using Transformative Experience to Promote Positive Affect and Conceptual Change in Students Learning About Biological Evolution. Sci. Educ. 97, 723-744 (2013).

45. Johri, A., Roth, W.-M. \& Olds, B. M. The role of representations in engineering practices: Taking a turn towards inscriptions. J. Eng. Educ. 102, 2-19 (2013).

46. Hertzberg, J., Leppek, B. R. \& Gray, K. E. Art for the Sake of Improving Attitudes towards Engineering. Am. Soc. Eng. Educ. (2012).

47. Goodman, K., Hertzberg, J. \& Finkelstein, N. Aesthetics and Expanding Perception in Fluid Physics. in Frontiers in Education 1747-1751 (2015).

doi:10.1109/FIE.2015.7344311

48. Goodman, K., Ewen, H. P., Harriman, J. W. \& Hertzberg, J. Aesthetics of Design : a Case Study of a Course (\#12312). in ASEE Annual Conference and Exposition, Conference Proceedings 122nd ASEE, 1-16 (2015).

49. Teitelbaum, M. S. Falling Behind? Boom, Bust, and the Global Race for Scientific Talent. (Princeton UP, 2014).

50. Ennis, T. et al. GoldShirt Transitional Program : Creating Engineering Capacity and Expanding Diversity through a Performance-Enhancing Year. Am. Soc. Eng. Educ. 1-16 (2010). 